\title{
A Novel Role for MiR-520a-3p in Regulating EGFR Expression in Colorectal Cancer
}

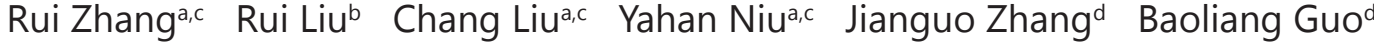 \\ Chen-Yu Zhanga,c Jing Lij ${ }^{a, c}$ Jie Yang ${ }^{c} \quad X_{i}$ Chen ${ }^{a, c}$ \\ aState Key Laboratory of Pharmaceutical Biotechnology, Jiangsu Engineering Research Center for \\ MicroRNA Biology and Biotechnology, NJU Advanced Institute for Life Sciences (NAILS), School of \\ Life Sciences, Nanjing University, Nanjing, ' ${ }^{\mathrm{T}}$ Tianjin Medical University Cancer Institute and Hospital, \\ National Clinical Research Center for Cancer, Key Laboratory of Cancer Prevention and Therapy, \\ Tiyuanbei, 'State Key Laboratory of Pharmaceutical Biotechnology, School of Life Sciences, Nanjing \\ University, Nanjing, ${ }^{\mathrm{d} T}$ The Second Affiliated Hospital of Harbin Medical University, Harbin, China
}

\section{Key Words}

MicroRNA • EGFR • Colorectal cancer $\cdot$ MiR-520a-3p

\begin{abstract}
Background/Aims: MicroRNAs (miRNAs) have been consistently demonstrated to be involved in colorectal cancer as either tumour oncogenes or tumour suppressors. However, the detailed role of miR-520a-3p in colorectal cancer remains poorly understood. Methods: Quantitative RT-PCR and western blotting assays were used to measure miR-520a-3p and EGFR expression levels in colorectal cancer tissues, respectively. Luciferase reporter assay was employed to validate the direct targeting of EGFR by miR-520a-3p. Cell migration, apoptosis and cell cycle assays were performed to analyse the biological functions of miR-520a-3p and EGFR in colorectal cancer cells. In vivo experiment was performed to analyse the effects of miR-520a-3p and EGFR on the growth of colorectal cancer xenografts in mice. Results: In this study, we found that miR-520a-3p was most likely to target the EGFR 3'-UTR, which was experimentally validated. In addition, we investigated the biological effects of EGFR inhibition by miR-520a-3p both in vitro and in vivo and found that miR-520a-3p could suppress cell migration, promote apoptosis, lead to colorectal cancer cell cycle arrest at the G0/G1 phase, and decelerate tumour growth in xenograft mice, potentially by targeting EGFR. Conclusions: This study highlights a tumour suppressor role for miR-520a-3p in colorectal cancer via the regulation of EGFR expression. Thus, miR-520a-3p may be a novel molecular therapeutic target for colorectal cancer.




\section{Cellular Physiology Cell Physiol Biochem 2017;42:1559-1574

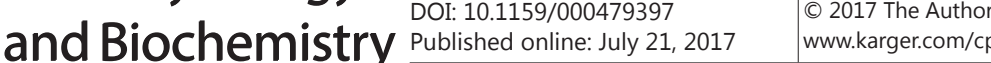 \\ Zhang et al.: Tumour Suppressor Role for miR-520a-3p in Colorectal Cancer}

\section{Introduction}

Colorectal cancer is one of the most common malignancies worldwide. Approximately 1.2 million patients worldwide have been diagnosed with colorectal cancer, and more than 600,000 patients have died directly or indirectly because of colorectal cancer [1]. In recent years, with continuous improvements in living standards, eating habits and diet, population ageing, morbidity and mortality rates of colorectal cancer have also been on the rise. Recently, the colorectal cancer field has led the way in the development of targeted therapies because biomarkers have begun to play an increasingly important role in the detection and management of patients with colorectal cancer [2]. The human epidermal growth factor receptor (EGFR) protein regulates cancer cell growth and apoptosis and has been validated as a relevant therapeutic target in several human cancers, including colorectal cancer $[3,4]$. The accumulation of EGFR in colorectal cancer has been widely reported [5, 6]. In recent years, new anticancer drugs that target EGFR have been developed and have demonstrated a prominent efficacy in the treatment of colorectal cancer. Two representative examples of such drugs are cetuximab and panitumumab [7-9]. However, only a small percentage of colorectal cancer patients are sensitive to anti-EGFR therapy, and even those who initially respond to therapy are limited by the emergence of secondary EGFR mutations or other drug resistance mechanisms $[10,11]$. Novel targeted drugs that efficiently inhibit all EGFR mutations in colorectal cancer patients are urgently needed.

MicroRNAs (miRNAs) are a class of endogenous noncoding RNAs that are typically 22 nucleotides in length and function primarily by targeting the 3'-untranslated region (3'-UTR) of specific mRNAs, thus silencing gene expression by either translational repression or direct mRNA degradation [12]. Through these post-transcriptional gene regulation mechanisms, miRNAs regulate a wide range of biological processes, including cell apoptosis and differentiation, migration, apoptosis, development and metabolism [13-15]. Accumulating evidence has shown aberrant miR-520 expression in tissue samples from with many types of human malignant tumours [16]. The miR-520 family acts as a tumour suppressor in many human cancers. For example, miR-520d-5p, a member of the miR-520 family, has been reported to act as anti-onco-miRNAs in colorectal cancer [17].

In this study, we showed that miR-520a-3p expression was negatively associated with EGFR in colorectal cancer tissues and cell lines. By using gain-of-function and loss-offunction studies, we confirmed the tumour suppressor function of miR-520a-3p both in vitro and in vivo. These findings suggest that treatments involving miR-520a-3p have potential therapeutic implications for the cure of colorectal cancer.

\section{Materials and Methods}

\section{Tissue samples}

Eight colorectal cancer patients who underwent surgical resection at the Affiliated Drum Tower Hospital of Nanjing University Medical School (Nanjing, China) were enrolled in this study. Paired colorectal cancer tissues were confirmed to be colorectal cancer pathologically. All patients provided written consent of their information and samples to be used in this study, and this study was approved by the Ethics Committee of Nanjing University. The clinical features of the patients are listed in Table 1.

\section{Cell culture}

The human colorectal cancer cell line SW480 and HT29 were obtained from the Shanghai Institute of Cell Biology at the Chinese Academy of Sciences (Shanghai, China). The SW480 and HT29 cells were cultured in RPMI-1640 (Gibco, Carlsbad, CA, USA) supplemented with 10\% foetal bovine serum (FBS) (GIBCO). All cells were incubated at $37^{\circ} \mathrm{C}$ in $5 \% \mathrm{CO}_{2}$ and a water-saturated atmosphere.

Overexpression or knockdown of miR-520a-3p

The miR-520a-3p mimic, miR-520a-3p inhibitor and negative control RNAs were obtained from Ruibobio, Guangzhou, China. SW480 or HT29 cells were seeded in 6-well plates and then synthetic RNAs 


\section{Cellular Physiology Cell Physiol Biochem 2017;42:1559-1574 \begin{tabular}{c|l|l}
\hline DOI: 10.1159/000479397 & $\begin{array}{l}\text { () } 2017 \text { The Author(s). Published by S. Karger AG, Basel } \\
\text { www.karger.com/cpb }\end{array}$
\end{tabular}}

Zhang et al.: Tumour Suppressor Role for miR-520a-3p in Colorectal Cancer

Table 1. Clinical features of colorectal cancer patients

\begin{tabular}{ccccc}
\hline Case number & Age & Gender & Pathological Stage & Tumor Subtype \\
\hline 1 & 64 & M & II(T3,N0,M0) & Adenocarcinoma \\
2 & 88 & M & II(T3,N0,M0) & Adenocarcinoma \\
3 & 65 & F & III(T3,N2,M0) & Adenocarcinoma \\
4 & 58 & M & II(T3,N1,M0) & Adenocarcinoma \\
5 & 74 & F & II(T3,N0,M0) & Adenocarcinoma \\
6 & 55 & F & II(T3,N0,M0) & Adenocarcinoma \\
7 & 51 & M & II(T3,N0,M0) & Adenocarcinoma \\
8 & 43 & M & II(T3,N1,M0) & Adenocarcinoma \\
\hline
\end{tabular}

were transfected into SW480 or HT29 cells using Lipofectamine 2000 (Invitrogen, Carlsbad, CA, USA) according to the manufacturer's protocols.

\section{RNA isolation and quantitative RT-PCR}

Total RNA from the cultured cells and tissues was isolated using TRIzol Reagent (Sigma, St. Louis, MO, USA) following to the manufacturer's protocols. Real-time PCR for EGFR and GAPDH was measured using an Applied Biosystems 7300 Sequence Detection System (Applied Biosystems) and SYBR green dye (Invitrogen, Carlsbad, CA, USA). The primers for EGFR and GAPDH were as follows: EGFR (sense): 5'-TTGCCGCAAAGTGTGTAACG-3' and EGFR (antisense): 5'-GTCACCCCTAAATGCCACCG-3'; and GAPDH (sense): 5'-GATATTGTTGCCATCAATGAC-3' and GAPDH (antisense): 5'-TTGATTTTGGAGGGATCTCG-3'.

The miR-520a-3p expression was performed with TaqMan miRNA probes (Applied Biosystems). The detailed description of experimental details is given in our previous article [18].

\section{Target predictions}

Target genes were predicted with three algorithms from TargetScan (http://genes.mit.edu/ targetscan/); miRWalk (http://www.umm.uni-heidelberg.de/apps/zmf/mirwalk/index.html); and miRanda (http://www.microrna.org). Then, miRNAs which predicted at least by two algorithms were selected and the RNAhybrid software was used to assess whether the binding of the miRNA to its target was stable. For the miRNA and target gene binding sites, we mainly set two rules: 1 . minimum binding free energy of miRNA and its binding site cannot be higher than $-20 \mathrm{kcal} / \mathrm{mol}$; 2 . seed sequence of the miRNA must be completely complementary and not mismatched. Finally, we refer to the relevance of miRNA and cancer and its negative correlation with the target gene selecting the appropriate miRNA for further study.

\section{Plasmid construction and luciferase assay}

The EGFR 3'-UTR sequence containing the presumed miR-520a-3p binding sites or mutated binding sites were inserted into the p-MIR-reporter plasmid (Ambion). Then, SW480 cells were seeded into 12well plates, and co-transfected with presumed miR-520a-3p binding sites or mutated binding sites, $\beta$ galactosidase expression plasmid (used as a transfection control), and scrambled ncRNA, miR-520a-3p mimic or miR-520a-3p inhibitor using Lipofectamine 2000 (Invitrogen, Carlsbad, CA, USA). Twenty-four hours after the transfection, cells were measured by a luciferase assay kits (Promega) according to the manufacturer's protocols.

\section{Protein extraction and Western blotting}

Total protein was isolated from cells lysed with RIPA lysis buffer (Beyotime, Shanghai, China) supplemented with protease inhibitor cocktail (Thermo Scientific) and the protein concentration was measured by a BCA protein assay kit (Pierce, Rockford, IL, USA). All protein levels were quantified by Western blot analysis of whole cell extracts using an EGFR antibody (Abcam Biotechnology). GAPDH antibody (Santa Cruz Biotechnology) was used as the control to normalize the relative expression level of EGFR.

Cell migration assay

Cell migration assays were performed using 24-Well matrigel-coated chambers (Millipore) containing $8-\mu \mathrm{m}$ pore membranes. Cells were harvested $24 \mathrm{~h}$ after transfection and then seeded to the upper chamber $\left(2 \times 10^{4}\right.$ cells/well) with serum-free RPMI-1640 and 500 ul of RPMI-1640 plus $10 \%$ FBS was placed in the 


\section{Cellular Physiology Cell Physiol Biochem 2017;42:1559-1574

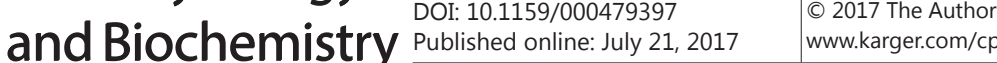

Zhang et al.: Tumour Suppressor Role for miR-520a-3p in Colorectal Cancer

lower compartment to stimulate cell migration. Twenty-four hours later, the remaining cells were scraped out from the upper face of the filters by cotton swabs and stained with crystal violet $(0.1 \%)$. The cell number of the migrant cells was counted under a microscope (BX51 Olympus, Japan).

\section{Cell cycle analysis}

Cells were trypsinized and fixed in $70 \%$ ethanol at $-20^{\circ} \mathrm{C}$ overnight, and the DNA content was measured following the manufacturer's protocol (Molecular Probes Inc.) and analysed using a FACS flow cytometer (BD Biosciences, San Jose, CA).

\section{Apoptosis}

To induce apoptosis, cells transfected with the abovementioned RNAs or plasmids were treated with LPS (400 ng/mL, Sigma). Apoptotic cells were detected by a BD Biosciences Annexin V Apoptosis detection kit according to the manufacturer's instructions. Briefly, cells were collected and stained with $0.5 \mathrm{~mL}$ of binding buffer containing annexin V-FITC and propidium iodide for $20 \mathrm{~min}$ in the dark at room temperature, which were subsequently analysed using a FACS flow cytometer (BD Biosciences, San Jose, CA).

\section{Animal studies}

Six-week-old male athymic BALB/c female nude mice (nu/nu) were obtained from the Model Animal Research Centre of Nanjing University (Nanjing, China). All animal experiments were approved by the Animal Care Committee of Nanjing University. Then, mice were equally divided into 3 groups (5 mice/ group) and injected subcutaneously with $1 \times 10^{4} \mathrm{HT} 29$ cells which infected with control lentivirus or miR520a-3p lentivirus, EGFR overexpression plasmid or co-transfected with miR-520a-3p lentivirus and EGFR overexpression plasmid. Mice were sacrificed one month later, and the weights of the mice and tumours were measured. Tumours were taken to perform western blot analysis and qRT-PCR analyses and tumour section slides were subjected to Haematoxylin and Eosin (H\&E) staining or immunohistochemical (IHC).

\section{Statistical analysis}

All experiments were repeated three to five times. Data are presented as the mean \pm SE. Statistical significance was considered at $\mathrm{P}<0.05$ using the Student's t-test.

\section{Results}

\section{Up-regulation of EGFR protein in human colorectal cancer tissues}

In agreement with previous studies, EGFR was found to be consistently overexpressed in human colorectal cancer tissues. As shown in Fig. 1A and 1B, EGFR protein levels were significantly increased in colorectal cancer tissues compared to adjacent normal tissues in 8 pairs of colorectal cancer tissues and adjacent normal tissues. Moreover, we analysed EGFR mRNA expression in the same colorectal cancer tissue pairs by quantitative RT-PCR (qRTPCR). EGFR mRNA expression was slightly increased in colorectal cancer tissues compared to adjacent normal tissues (Fig. 1C). This disparity between EGFR protein and mRNA level in colorectal cancer tissues strongly suggests that EGFR protein level may be involved in a post-transcriptional mechanism.

\section{Identification of miR-520a-3p as a potential miRNA that targets EGFR}

MiRNAs are crucial regulators in colorectal cancer. Multiple target prediction programs were applied to identify potential miRNAs that target EGFR. Based on the species conservation and the minimum free energy (MFE) of its binding sites as well as its cancer correlations, miR-520a-3p was highlighted for further investigation. Figure $2 \mathrm{~A}$ illustrated the predicted interaction between miR-520a-3p and the target site in the EGFR 3'-UTR and the minimum free energies of these binding sites are $-20.8,-19.7$ and $-17 \mathrm{kcal} / \mathrm{mol}$.

To investigated whether miR-520a-3p expression levels are inversely correlated with EGFR expression in colorectal cancer tissues, same 8 pairs of colorectal cancer tissues and adjacent normal tissues were used to measure the expression levels of miR-520a-3p and the 


\section{Cellular Physiology Cell Physiol Biochem 2017;42:1559-1574

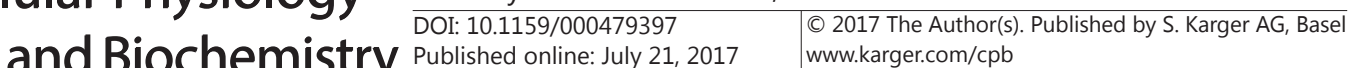

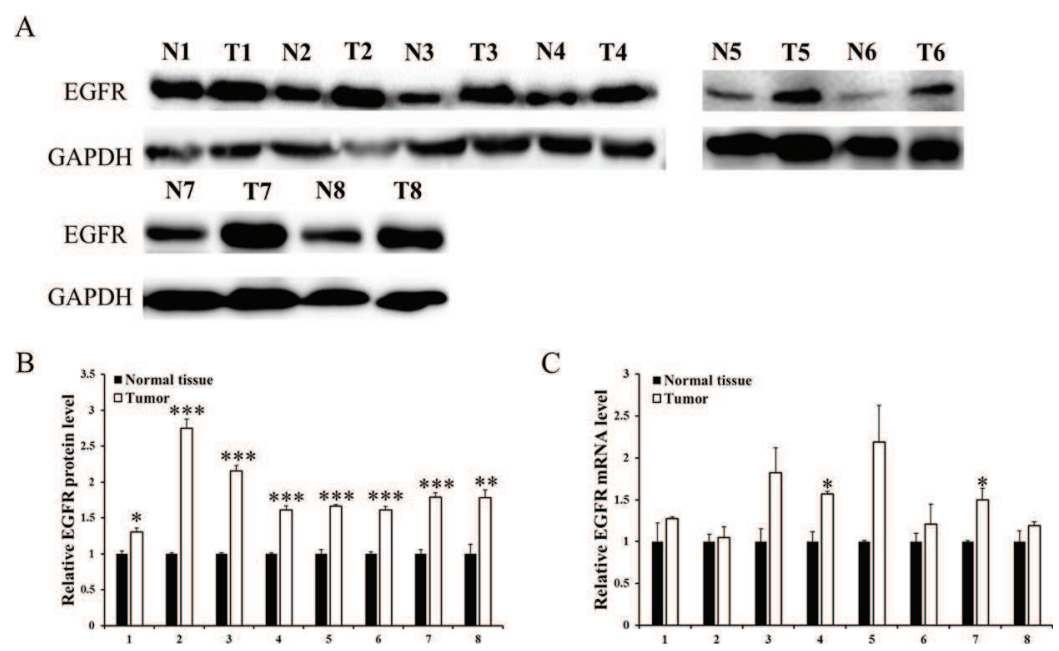

Fig. 1. The expression of EGFR in human colorectal cancer tissues. (A) Western blot analysis of the expression levels of EGFR protein in 8 pairs of colorectal cancer tissues (T) and matched normal tissues (N). (B) Relative abundance of the EGFR protein level in (A). (C) Quantitative RT-PCR analysis of the relative expression levels of EGFR mRNA in 8 pairs of colorectal cancer tissues (T) and matched normal tissues (N). ${ }^{*} \mathrm{P}<$ 0.05 ; $* * \mathrm{P}<0.01$; and ${ }^{* * *} \mathrm{P}<0.001$.

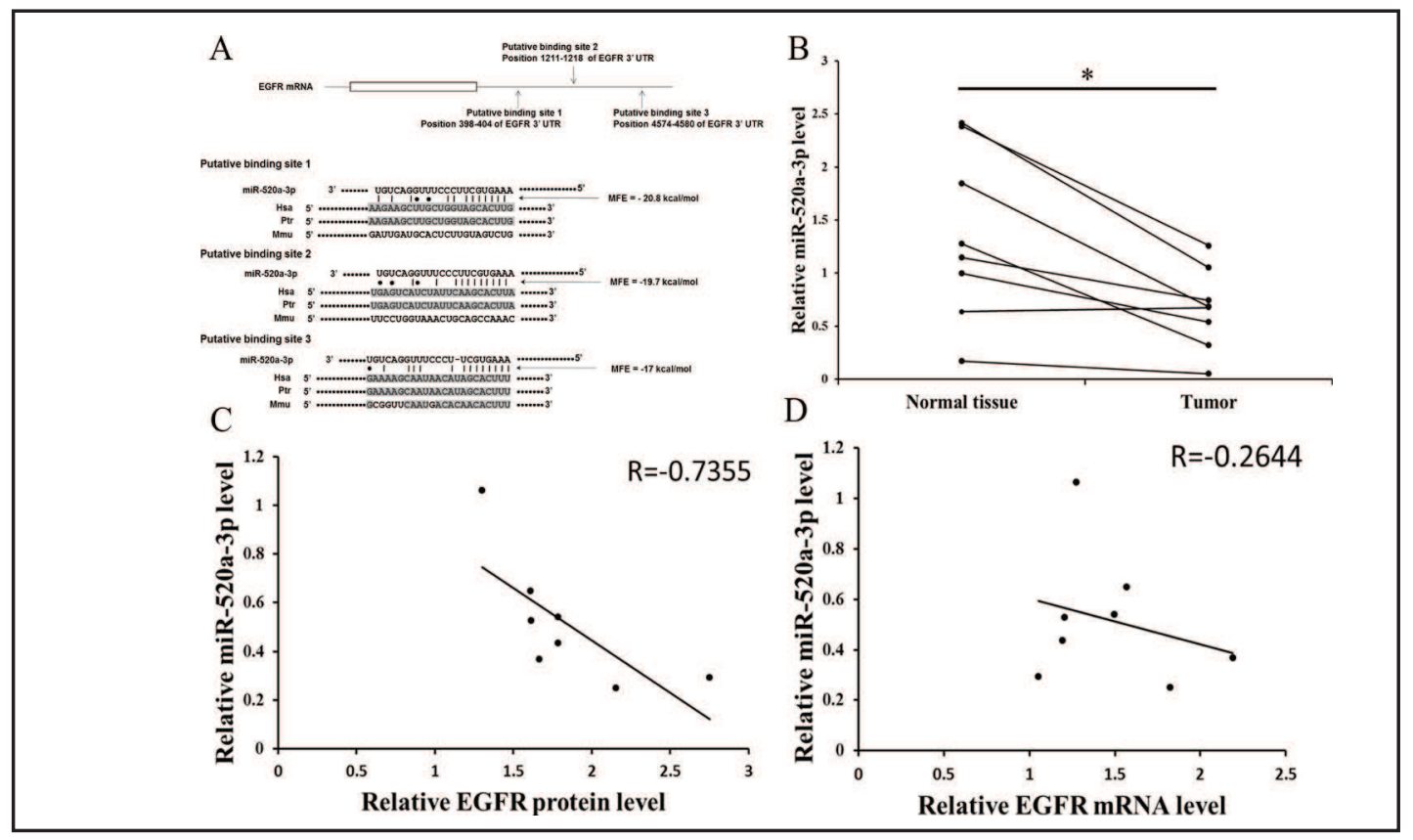

Fig. 2. Prediction of EGFR as a miR-520a-3p target. (A) Schematic description of miR-520a-3p binding sites in the EGFR 3'-UTR. Paired bases are indicated by a short black line, and G:U pairs are indicated by dots. The predicted free energy of each hybrid is indicated. Sequence alignment of the putative miR-520a-3p binding sites across species are marked by a grey background. (B) Quantitative RT-PCR analysis of the relative expression levels of miR-520a-3p in the same 8 pairs of colorectal cancer and matched normal tissues. (C) Pearson's correlation scatter plot of the fold change of miR-520a-3p and EGFR protein expression in human colorectal cancer tissue pairs. (D) Pearson's correlation scatter plot of the fold change of miR-520a-3p and EGFR mRNA in human colorectal cancer tissue pairs. ${ }^{*} \mathrm{P}<0.05$; ${ }^{* *} \mathrm{P}<0.01$; and ${ }^{* * *} \mathrm{P}<0.001$.

miR-520a-3p levels showed an consistently decrease in colorectal cancer tissues (Fig. 2B). An inverse correlation was observed between miR-520a-3p and EGFR protein levels (Fig. 


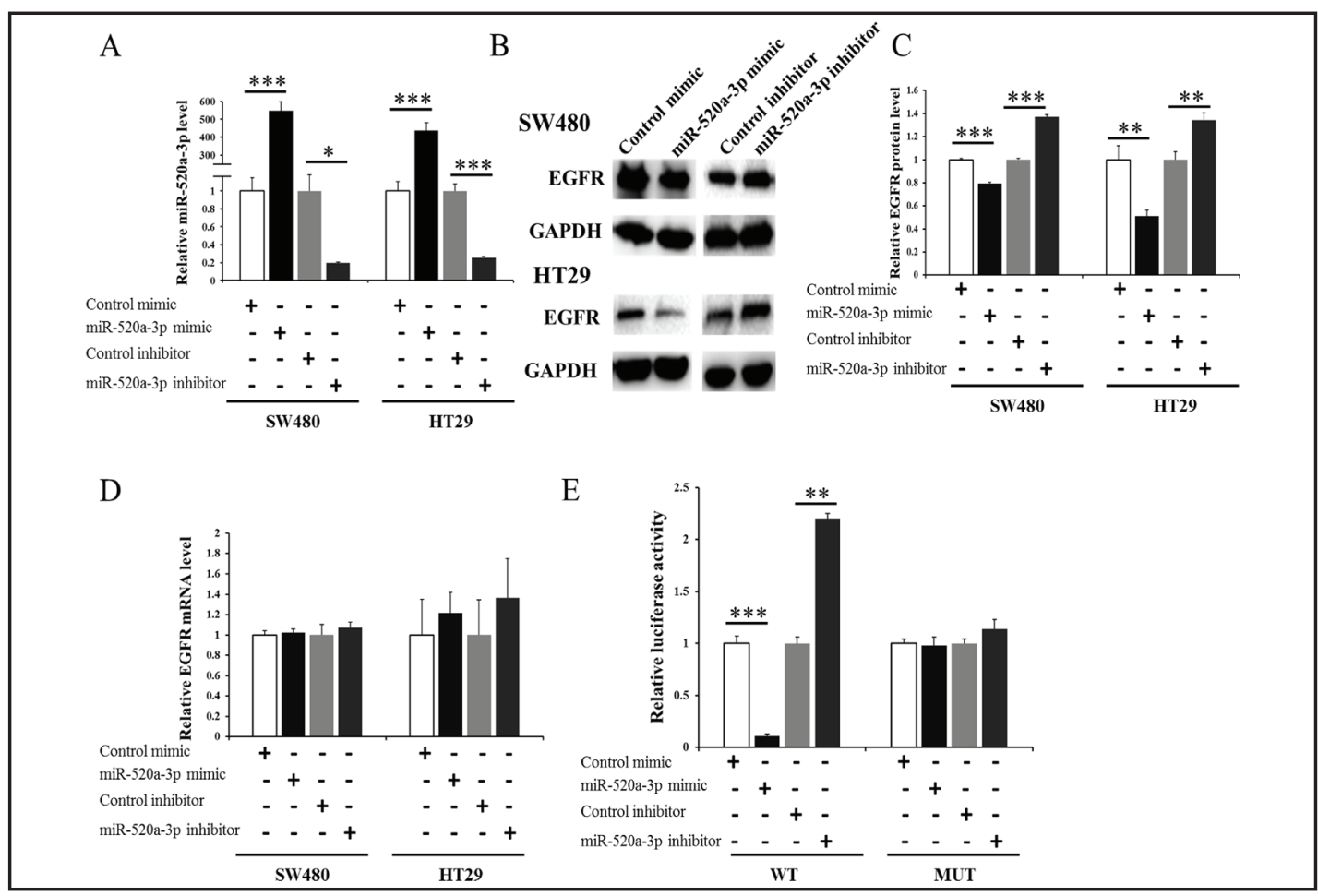

Fig. 3. MiR-520a-3p directly targets EGFR via translational repression. (A) Quantitative RT-PCR analysis of the relative expression levels of of miR-520a-3p in SW480 and HT29 cells that transfected with equal dose of control mimic, miR-520a-3p mimic, control inhibitor or miR-520a-3p inhibitor. (B) Western blot analysis of the expression levels of EGFR protein in SW480 and HT29 cells transfected with equal dose of control mimic, miR-520a-3p mimic, control inhibitor or miR-520a-3p inhibitor. (C) Relative abundance of EGFR in the experiments shown in (B). (D) Quantitative RT-PCR analysis of the expression levels of EGFR mRNA in SW480 and HT29 cells transfected with equal dose of control mimic, miR-520a-3p mimic, control inhibitor or miR-520a-3p inhibitor. (E) A firefly luciferase reporter containing either wild-type (WT) or mutant EGFR 3'-UTR was co-transfected into SW480 cells with a control mimic, miR-520a-3p mimic, control inhibitor or miR-520a-3p inhibitor. For comparison, luciferase activity in the ncRNA-transfected cells was set at 1 . The $\mathrm{y}$-axis shows arbitrary units representing the relative luciferase activity. ${ }^{*} \mathrm{P}<0.05$; ${ }^{* *} \mathrm{P}<0.01$; and ${ }^{* * *} \mathrm{P}<$ 0.001 .

2C) and an irregular alteration was observed between the miR-520a-3p and EGFR mRNA levels (Fig. 2D) in Pearson's correlation scatter plots. In order to further confirm this result, we analysed 200 pairs of colorectal cancer tissue samples from TGCA database to perform the correlation of miR-520a and EGFR mRNA by using Pearson's correlation scatter plots. As shown in Fig. 9, miR-520a-3p levels were consistently lower in CRC tissues, however there is irregular alteration between miR-520a and EGFR mRNA.

\section{MiR-520a-3p directly targets EGFR at the posttranscriptional level}

Furthermore, we performed a luciferase reporter assay to confirm that EGFR is directly regulated by miR-520a-3p through interactions at the 3'-UTR. The EGFR 3'-UTR sequence containing the presumed miR-520a-3p binding sites was cloned at a downstream position on the firefly luciferase reporter plasmid. The resulting plasmid was transfected into SW480 cells along with a transfection control plasmid ( $\beta$-gal) and miR-520a-3p mimic, miR-520a$3 p$ inhibitor or negative control RNAs (ncRNAs). As expected, the miR-520a-3p mimic decreased the luciferase activity to $11 \%$ of the baseline reporter construct luciferase activity, whereas the miR-520a-3p inhibitor increased the luciferase activity by 2.2-fold. Meanwhile, we introduced point mutations into the seed complementary sites (the core sequence that encompasses the first 2-8 bases from the mature miRNA 5'end) within the EGFR 3'-UTR 


\section{Cellular Physiology Cell Physiol Biochem 2017;42:1559-1574 \begin{tabular}{ll|l} 
DOI: 10.1159/000479397 & $\begin{array}{l}\text { () } 2017 \text { The Author(s). Published by S. Karger AG, Basel } \\
\text { www.kargercom/cpb }\end{array}$
\end{tabular} \\ Zhang et al.: Tumour Suppressor Role for miR-520a-3p in Colorectal Cancer}

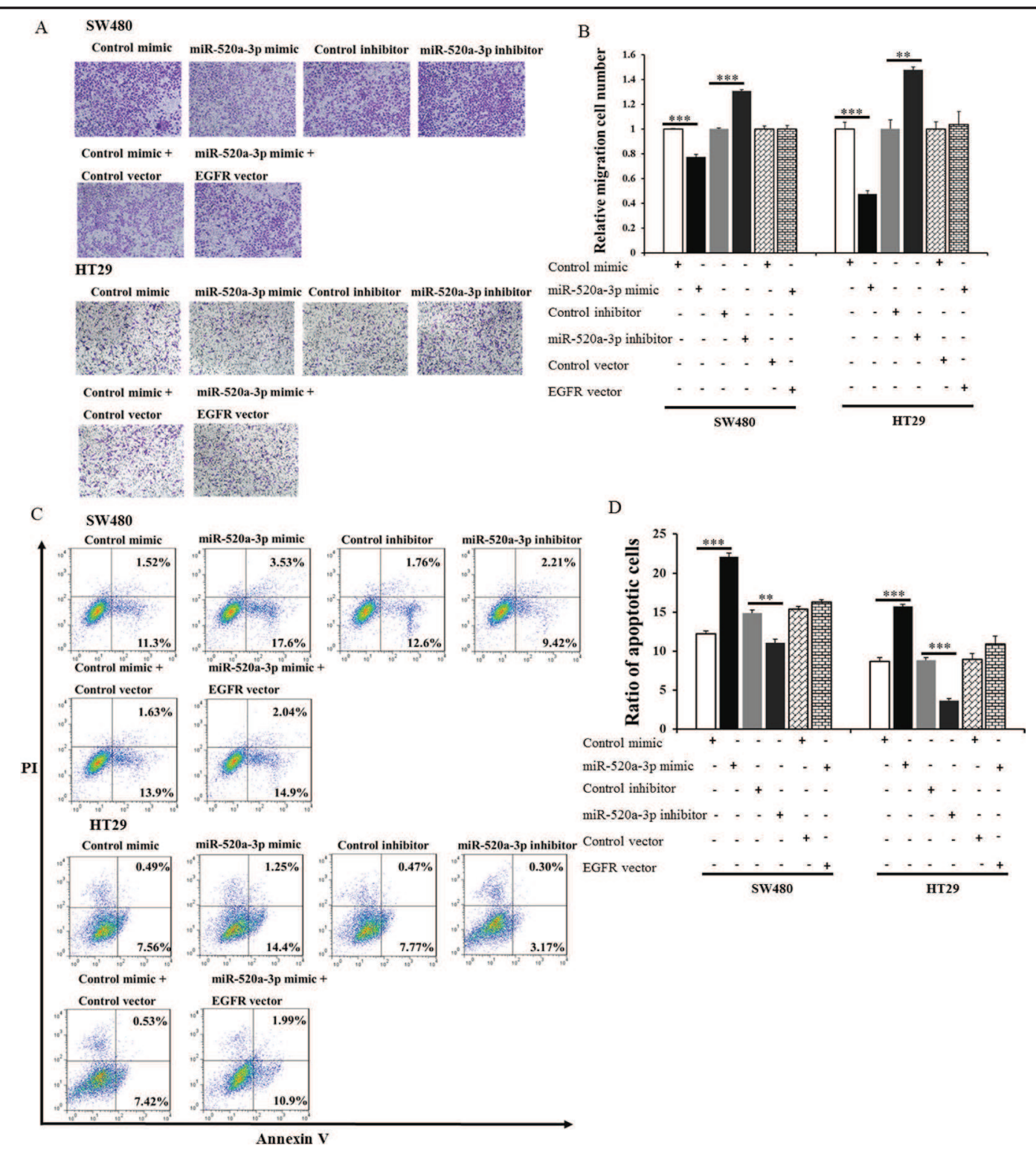

Fig. 4. Effects of miR-520a-3p and EGFR on colorectal cancer cell migration and apoptosis. (A) SW480 and HT29 cells that were transfected with synthetic RNAs or plasmid. (B) Relative abundance of migrated cells in the experiments shown in (A). (C) The effect of control mimic, miR-520a-3p mimic, control inhibitor or miR-520a-3p inhibitor, or with an equal dose of control mimic plus control plasmid or miR-520a-3p mimic plus EGFR overexpression plasmid on cell apoptosis in SW480 and HT29 cells. (D) Relative abundance of the apoptotic cells in the experiments shown in (C). ${ }^{*} \mathrm{P}<0.05$; ${ }^{* *} \mathrm{P}<0.01$; and ${ }^{* * *} \mathrm{P}<0.001$.

of to eliminate the predicted miR-520a-3p binding site. Mutations in complementary seed sites result in no affection by miR-520a-3p overexpression or knockdown (Fig. 3E). These findings strongly indicate that miR-520a-3p can directly recognize the binding site in the EGFR 3'-UTR and mediate the post-transcriptional inhibition of the EGFR gene.

Theoretically, miRNAs silence target gene expression by two different mechanisms, namely, post-transcriptional repression and mRNA degradation. Thus, we next sought to confirm which mechanism miR-520a-3p uses to modulate EGFR expression. We transfected SW480 cells with equal doses of scrambled ncRNA, miR-520a-3p mimic or miR-520a$3 p$ inhibitor and analysed the expression levels of EGFR mRNA by qRT-PCR at 24 h post- 


\section{Cellular Physiology Cell Physiol Biochem 2017;42:1559-1574 \begin{tabular}{ll|l} 
and Biochemistry $10.1159 / 000479397$ & $\begin{array}{l}\text { D } 2017 \text { The Author(s). Published by S. Karger AG, Basel } \\
\text { www.karger.com/cpb }\end{array}$ \\
\hline
\end{tabular} \\ Zhang et al.: Tumour Suppressor Role for miR-520a-3p in Colorectal Cancer}

Fig. 5. MiR-520a-3p regulates the cell cycle through EGFR. (A) SW480 and HT29 cells were transfected with synthetic RNAs or plasmid. The percentages of cells in the G0/G1, S and G2/M phases were determined by flow cytometry. (B-G) Bar graphs illustrate the quantification of the cell cycle. ${ }^{*} \mathrm{P}<0.05$; ${ }^{* *} \mathrm{P}<0.01$; and $* * * \mathrm{P}<0.001$.

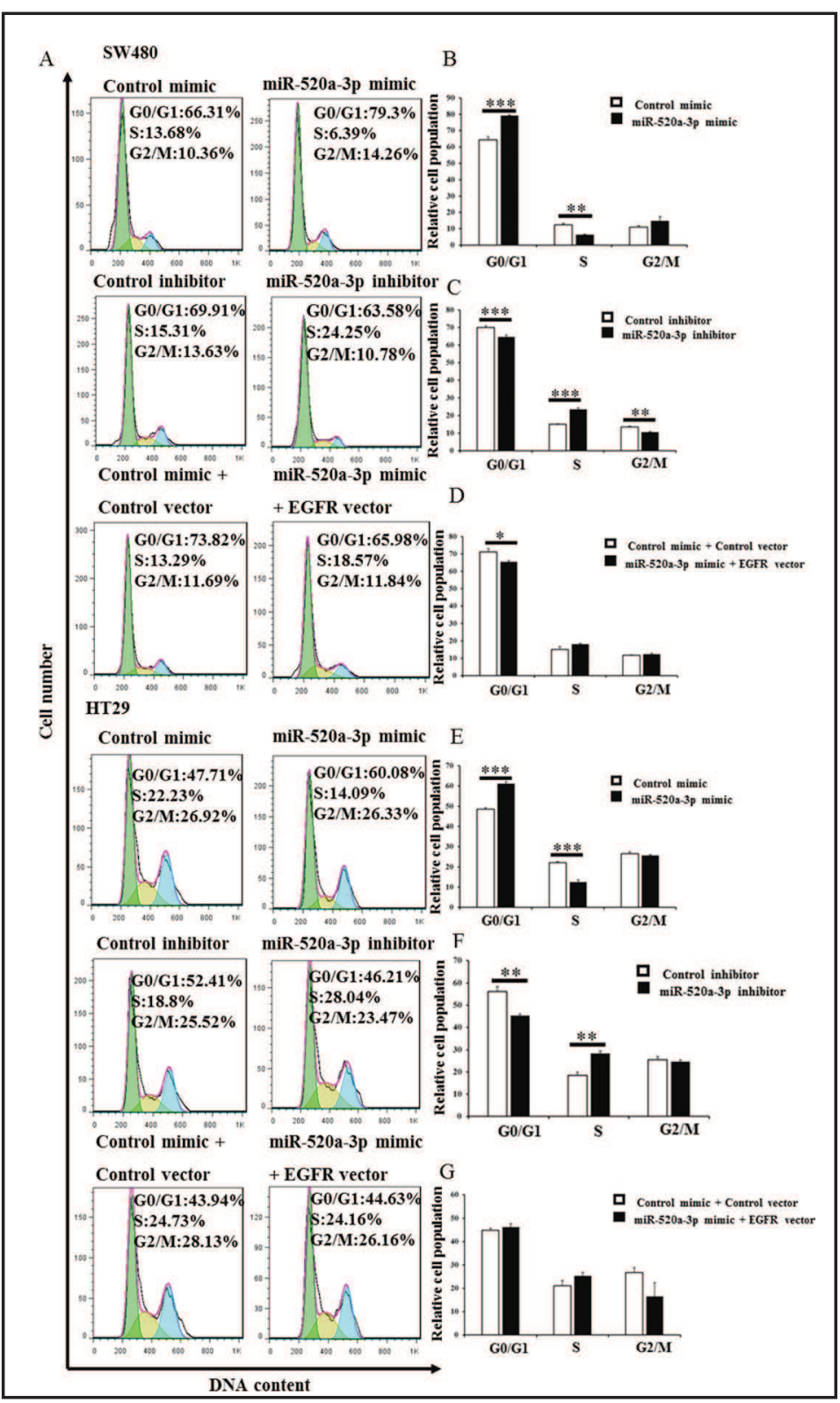

transfection. The efficient overexpression or knockdown of miR-520a-3p in SW480 cells is shown in Fig. 3A. However, no significant changes in EGFR mRNA expression levels were observed in miR-520a-3p mimic- or miR-520a-3p inhibitor-transfected cells compared with those transfected with corresponding scrambled ncRNAs (Fig. 3D). However, when we repeated the above experiments to determine whether the overexpression or knockdown of miR-520a-3p had an effect on EGFR protein expression by Western blotting at $24 \mathrm{~h}$ posttransfection, we found that cells transfected with miR-520a-3p mimic showed reduced EGFR protein levels relative to cells transfected with scrambled ncRNA. In contrast, the protein levels of EGFR were significantly increased in miR-520a-3p inhibitor-transfected cells compared with those transfected with scrambled ncRNA (Fig. 3B and 3C). Similar results were obtained in the colorectal cancer cell line HT29 (Fig. 3A-3D). We also performed the luciferase assays and the Western blots with miR-372 which have the same seed sequences with miR-520a-3p in SW480 cells. Similar results were obtained in miR-372 transfected cells (Fig. 8). These findings demonstrate that miR-520a-3p is capable of regulating EGFR through post-translational repression and this targeting may be a shared target by several family members with the same seed. 


\section{Cellular Physiology \\ Cell Physiol Biochem 2017;42:1559-1574 \begin{tabular}{c|c|c|c|c|c|}
\hline DOI: 10.1159/000479397 & (c) 2017 The Author(s). Published by S. Karger AG, Basel
\end{tabular}

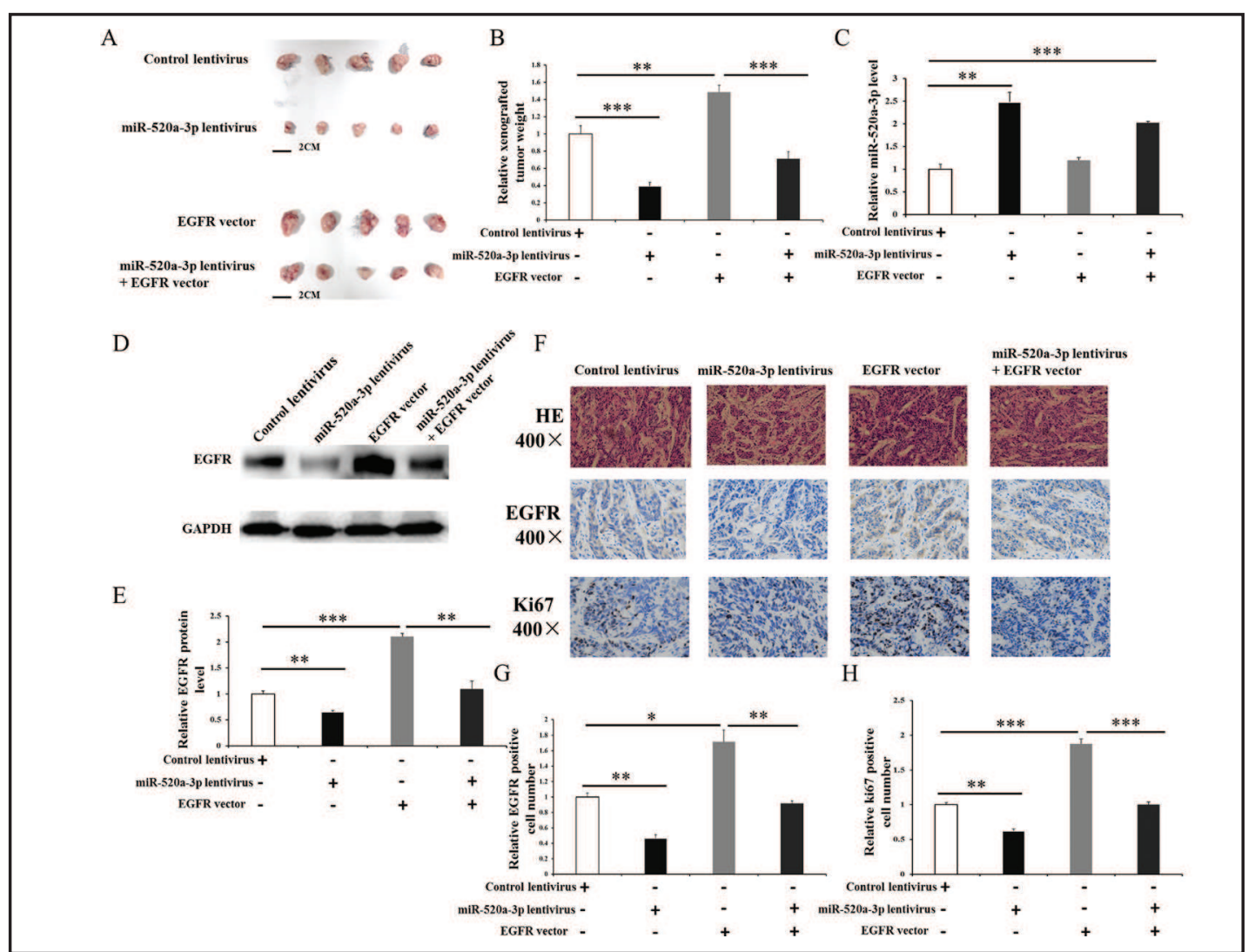

Fig. 6. Effects of miR-520a-3p and EGFR on the growth of colorectal cancer cell xenografted tumours in mice. (A) Representative images of the nude mice excised tumors. (B) Relative abundance of xenografted tumour weights. (C) Quantitative RT-PCR analysis of the expression levels of miR-520a-3p in tumours from the implanted mice. (D) Western blotting analysis of the expression levels of EGFR protein in tumours from the implanted mice. (E) Relative abundance of EGFR protein levels in the experiments shown in (D). (F) Representative of H\&E-stained sections and immunohistochemical staining for EGFR and Ki-67 in tumours from the implanted mice. ( $G$ and $H$ ) Relative abundance of EGFR and Ki-67 in the experiments shown in (F). ${ }^{*} \mathrm{P}<0.05 ;{ }^{* *} \mathrm{P}<0.01$; and ${ }^{* * *} \mathrm{P}<0.001$.

MiR-520a-3 and EGFR have opposite effects on colorectal cancer cells

To investigate whether miR-520a-3p affected the tumourgenesis of colorectal cancer cells, migration and cell apoptosis assays in colorectal cancer cells was conducted. SW480 and HT29 cells were transfected with equal doses of miR-520a-3p mimic, miR-520a-3p inhibitor, or corresponding scrambled ncRNAs. We first performed transwell assays to analyse the effect of miR-520a-3p on colorectal cancer cell migration (Fig. 4A and 4B). The transwell assay revealed that migratory capabilities were greatly decreased in SW480 and HT29 cells that were transfected with the miR-520a-3p mimic and increased in cells that were transfected with the miR-520a-3p inhibitor. The effects of miR-520a-3p on apoptosis were further illustrated by flow cytometric analysis. In SW480 and HT29 cells transfected with miR-520a-3p mimic, increased cell apoptosis was observed; in contrast, transfection with the miR-520a-3p inhibitor had the opposite effect on colorectal cancer cell apoptosis (Fig. 4C and 4D).

To investigate whether miR-520a-3p and EGFR expression can affect the cell cycle, miR520a-3p was overexpressed or knocked down in SW480 and HT29 cells, and the cells were examined by flow cytometer. Overexpression of miR-520a-3p following mimic transfection resulted in an increase in the population of cells in G0/G1 phase, with a concomitant decrease in the fraction of cells in S phase (Fig. 5A, 5B and 5E). In contrast, knockdown of miR-520a- 


\section{Cellular Physiology Cell Physiol Biochem 2017;42:1559-1574

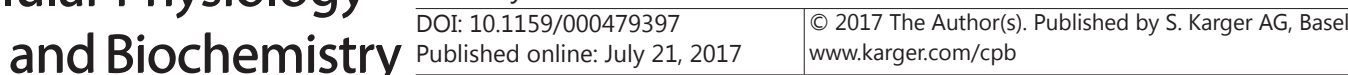 \\ Zhang et al.: Tumour Suppressor Role for miR-520a-3p in Colorectal Cancer}

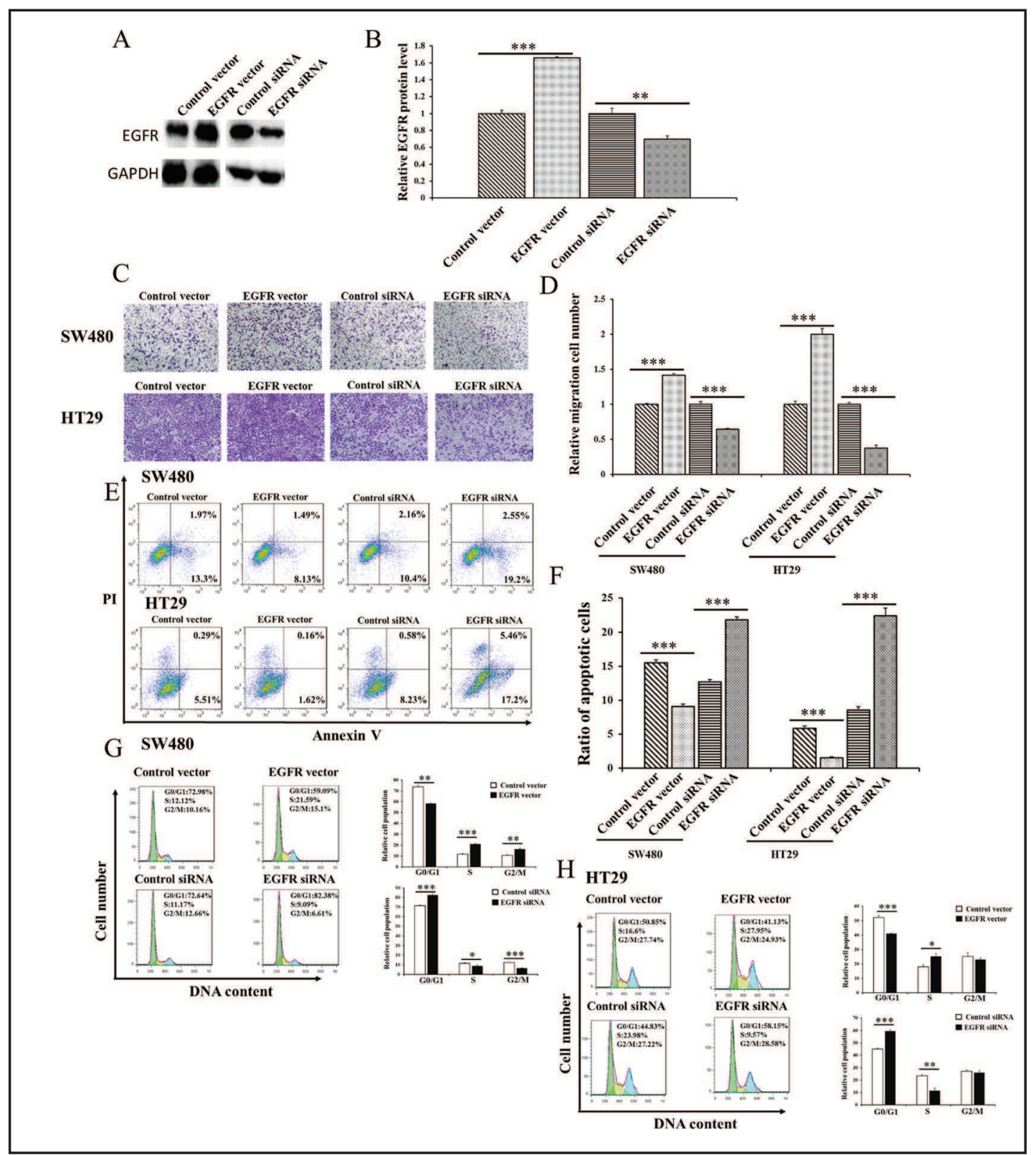

Fig. 7. Effect of EGFR on CRC cell migration, apoptosis and cell cycle. (A and B) Western blotting analysis of EGFR protein levels in SW480 cells transfected with control siRNA, EGFR siRNA, control plasmid or EGFR overexpression plasmid. A: representative images; B: quantitative analysis. (C and D) Transwell assays were performed to evaluate the effect of EGFR on the migration of SW480 or HT29 cells transfected with an equal dose of control siRNA, EGFR siRNA, control plasmid or EGFR overexpression plasmid. C: representative images. D: quantitative analysis. (E and F) Apoptosis assays were performed $24 \mathrm{~h}$ after the transfection of SW480 or H29 cells with an equal dose of control siRNA, EGFR siRNA, control plasmid or EGFR overexpression plasmid. E: representative images; F: quantitative analysis. ( $G$ and $H$ ) Cell cycle assays were performed $24 \mathrm{~h}$ after the transfection of SW480 or $\mathrm{H} 29$ cells with an equal dose of control siRNA, EGFR siRNA, control plasmid or EGFR overexpression plasmid. ${ }^{*} \mathrm{P}<0.05$; ${ }^{* *} \mathrm{P}<0.01$; and ${ }^{* * *} \mathrm{P}<0.001$.

$3 p$ in two colorectal cancer cell lines by a miR-520a-3p inhibitor led to a reduction of cells in G0/G1 phase (Fig. 5A, 5C and 5F). These results indicate that miR-520a-3p blocked cell cycle progression by arresting cells in G0/G1 phase. 


\section{Cellular Physiology Cell Physiol Biochem 2017;42:1559-1574 \begin{tabular}{l|l} 
DOI: 10.1159/000479397 & $\begin{array}{l}\text { C 2017 The Author(s). Published by S. Karger AG, Basel } \\
\text { www.karger.com/cpb }\end{array}$ \\
\hline
\end{tabular} \\ Zhang et al.: Tumour Suppressor Role for miR-520a-3p in Colorectal Cancer}

Fig. 8. MiR-372 directly targets EGFR. (A) A firefly luciferase reporter containing either wild-type (WT) or mutant EGFR 3'-UTR was co-transfected into SW480 cells with a control mimic, miR-372 mimic, control inhibitor or miR-372 inhibitor. For comparison, luciferase activity in the ncRNA-transfected cells was set at 1 . The $y$-axis shows arbitrary units representing the relative luciferase activity. (B) Western blot analysis of the expression levels of EGFR

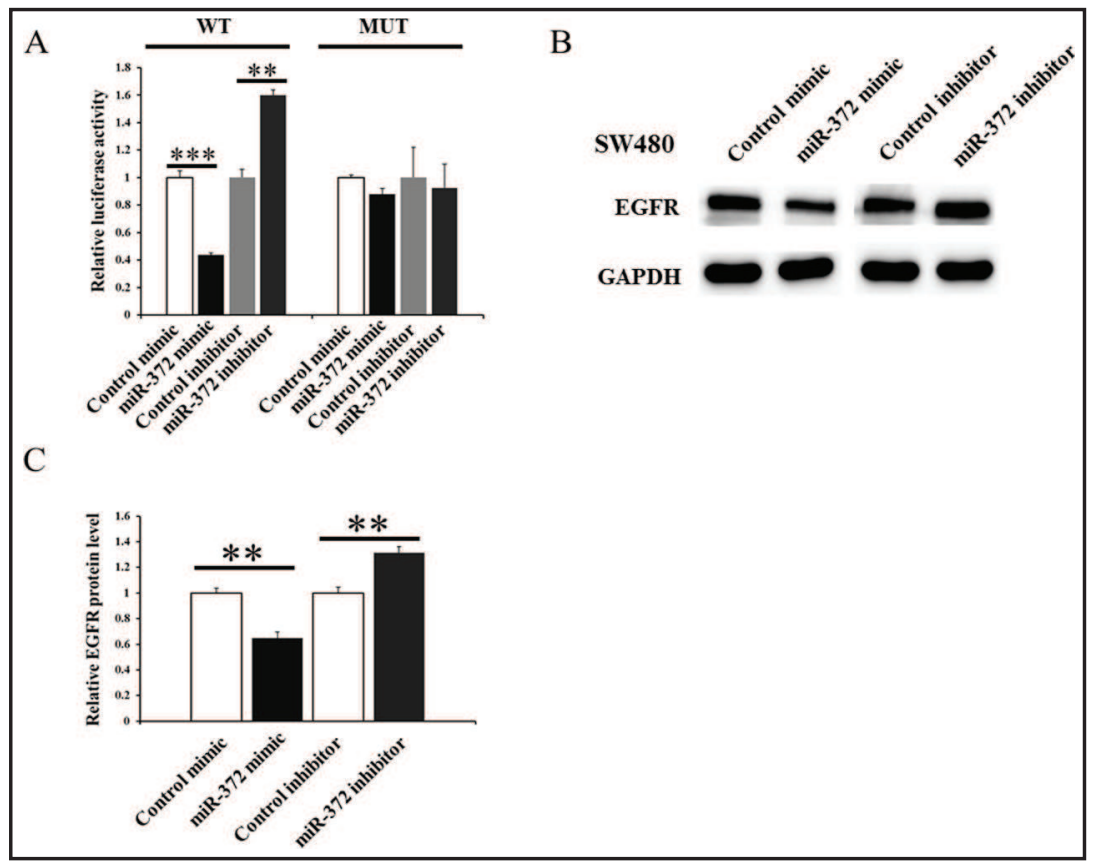
protein in SW480 cells transfected with equal dose of control mimic, miR-372 mimic, control inhibitor or miR-372 inhibitor. (C) Relative abundance of EGFR in the experiments shown in (B). ${ }^{*} \mathrm{P}<0.05$; ${ }^{* *} \mathrm{P}<0.01$; and ${ }^{* * *} \mathrm{P}<0.001$.

Because a single miRNA are generally thought to target multiple genes, it is essential to identify whether it is due to miR-520a-3p-mediated EGFR inhibition. The precise effect of the miR-520a-3p-EGFR axis on colorectal cancer cell apoptosis and migration was performed using a siRNA and an overexpression plasmid to down-regulate or up-regulate EGFR protein levels respectively. The efficient transfections in SW480 cells are shown in Fig. 7A-7B. EGFR down-regulation suppressed migration and increased apoptosis in SW480 and HT29 cells. Comparison with the fact that overexpression of EGFR had the opposite effect on cell migration and apoptosis (Fig. 7C-7F). We also analysed cell cycle profiles using flow cytometer after the transfection of SW480 and HT29 cells with EGFR siRNA or EGFR overexpression plasmid. Transfecting cells with EGFR siRNAs markedly increased the population of cells in G0/G1 phase; in contrast, overexpression of EGFR decreased the number of cells in G0/G1 phase but increased the number of cells in the $\mathrm{S}$ and G2/M phases (Fig. 7G and 7H). Thus, miR-520a-3p and EGFR have opposite biological functions in colorectal cancer cells.

To investigate whether the regulation of cell apoptosis, migration and cell cycle by miR520a-3p is an EGFR-dependent process, we co-transfected SW480 and HT29 cells with the EGFR overexpression plasmid and miR-520a-3p mimic. As we expected, cells co-transfected with the miR-520a-3p mimic and EGFR overexpression plasmid showed dramatically higher migration capabilities (Fig. 4A and 4B), lower apoptosis rates (Fig. 4C and 4D), and lower G0/G1 phase cell cycle arrest (Fig. 5A, 5D and 5G) compared to cells transfected with the miR-520a-3p mimic. Thus, restoration of EGFR expression can rescue the miR-520a-3pinduced suppression of cell migration as well as miR-520a-3p-induced cell apoptosis and G0/G1 phase cell cycle arrest. These results demonstrate that the targeting of EGFR is one mechanism by which miR-520a-3p exerts its tumour suppressor functions.

MiR-520a-3p and EGFR affect colorectal cancer growth in vivo

Finally, To further identify the influence of miR-520a-3p and EGFR on the growth of colorectal cancer xenografts in mice, HT29 cells which infected with a miR-520a-3p lentivirus, transfected cells with an EGFR overexpression plasmid, or co-transfected cells 


\section{Cellular Physiology Cell Physiol Biochem 2017;42:1559-1574 \begin{tabular}{ll|l} 
& DOI: 10.1159/000479397 & $\begin{array}{l}\text { @ 2017 The Author(s). Published by S. Karger AG, Basel } \\
\text { www.karger.com/cpb }\end{array}$ \\
\hline
\end{tabular} \\ Zhang et al.: Tumour Suppressor Role for miR-520a-3p in Colorectal Cancer}

Fig. 9. Pearson's correlation scatter plot of the fold change of miR-520a-3p and EGFR mRNA in 200 human colorectal cancer tissue pairs from TGCA database.

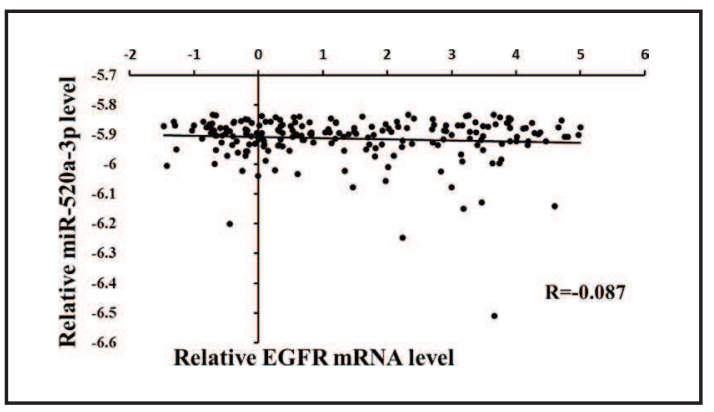

with a miR-520a-3p overexpression lentivirus and an EGFR overexpression plasmid were subcutaneously implanted into nude mice. Consistent with the results obtained in the in vitro experiment, we found that xenograft tumour growth in nude mice was significantly inhibited by miR-520a-3p and tumour growth in the EGFR-overexpressing group was dramatically promoted (Fig. 6A and 6B). Additionally, EGFR overexpression rescued the suppressive effects of miR-520a-3p, suggesting that miR-520a-3p suppresses tumour growth by silencing EGFR, however overexpression of EGFR does not completely abolish the suppressive tumour growth induced by miR-520a-3p (Fig. 6A and 6B). Next, we isolated total RNA and protein from the xenograft tumours and analysed. Tumours from the miR-520a-3p-overexpression group showed a significant increase in the expression of mature miR-520a-3p compared to tumours from the control group (Fig. 6C). Likewise, western blotting revealed a repressed EGFR expression in miR-520a-3p-overexpression group, whereas tumours from the EGFR-overexpression group showed an elevated EGFR expression (Fig. 6D and 6E). More importantly, tumours with both miR-520a-3p and EGFR displayed significantly increased EGFR expression compared to tumours overexpressing miR-520a-3p (Fig. 6D and 6E), suggesting that EGFR overexpression could rescue EGFR suppression caused by miR-520a$3 p$. Additionally, we performed H\&E staining or immunohistochemical staining of xenograft tumour tissues. H\&E staining confirmed that less cell mitosis in the miR-520a-3p lentivirus group, whereas more mitosis in the EGFR-overexpressing group. Xenograft tumour tissues with both miR-520a-3p and EGFR displayed more cell mitosis compared to xenografts tumour tissues implanted with miR-520a-3p lentivirus (Fig. 6F). Immunohistochemical staining also showed lower EGFR protein levels in tumour tissues from miR-520a-3p-overexpressing group, whereas tumours from the EGFR-overexpressing group revealed increased EGFR protein levels (Fig. 6F and 6G). Finally, the proliferative activity of tumour cells was assessed via Ki-67 immunohistochemical staining. Ki-67 indexes was decreased in the miR-520a-3p lentivirus-treated cells implanted group and was increased in the plasmid-transfected cells implanted group (Fig. 6F and 6H). Furthermore, EGFR overexpression rescued the antiproliferative achieves of miR-520a-3p overexpression and overexpression of EGFR does not completely abolish the anti-proliferative achieves induced by miR-520a-3p (Fig. $6 \mathrm{~F}$ and $6 \mathrm{H}$ ). These results firmly validating the tumour suppressor role of miR-520a-3p in colorectal cancer tumourgenesis is achieved by targeting EGFR.

\section{Discussion}

In recent years, it was found that miRNAs and tumour occurrence as well as development are closely related [19-21]. Compared with normal tissues, the expression of miRNA in tumour tissue markedly changes; miRNA interacts with the traditional tumour suppressor genes and proto-oncogenes and plays a dual role in tumourgenesis and development [22, 23]. MiRNAs can function as an oncogene, and the targeting of tumour suppressor genes by these oncogenic miRNAs provides favourable conditions for tumour growth, metastasis and infiltration [24, 25]. On the other hand, miRNAs can also have tumour-suppressive function, and the targeting of oncogenes by these miRNAs can contribute to tumour apoptosis, 


\section{Cellular Physiology Cell Physiol Biochem 2017;42:1559-1574 $\begin{array}{ll}\text { DOI: 10.1159/000479397 } & \text { 2 2017 The Authorf } \\ \text { www.karger.com/cp }\end{array}$ \\ Zhang et al.: Tumour Suppressor Role for miR-520a-3p in Colorectal Cancer}

differentiation and treatment [26-28]. As a consequence of the important functions mediated by miRNAs in cancer cells, potential therapeutic approaches that target this pathway have recently attracted attention [29-31]. To date, there are three main approaches to potential miRNA-targeting therapies: expression vectors (miRNA sponges), small-molecule inhibitors and synthetic oligonucleotides [32]. For example, aberrantly activated miRNAs can be silenced using antagomirs, and re-expression of miRNAs that are lost in cancers can be achieved by the induction of miRNA mimics $[18,33,34]$. It has been found that aberrant expression of the miR-520 family occurs in malignant tumours, and transcripts in this miRNA family have been identified as key regulators of oncogenes [35]. Reduced expression of miR-520 family transcripts was first found in breast cancer, in which miR-520 functions as a tumour suppressor in oestrogen receptor-negative breast cancer by targeting the NF- $\kappa \mathrm{B}$ and TGF- $\beta$ signalling pathways [35]. The miR-520 family is also down-regulated in colorectal cancer. As a member of the miR-520 family, miR-520d-5p suppresses tumour growth and metastasis in colorectal cancer by targeting CTHRC1 [17]. A recent study showed that miR$520 \mathrm{~g}$ inhibits proliferation and induces apoptosis in oesophageal squamous cell cancer by down- regulating CRCT1 [16]. In contrast, it was revealed to target CD44 in breast cancer and promote tumour invasion as well as metastasis [36]. Interestingly, a similar phenomenon was also found in prostate cancer where miR-520c could enhance the invasion of prostate cancer cells by suppressing CD44 translation [37]. Here, we show that miR-520a-3p can suppress migration and promote apoptosis in vitro and suppress tumour growth in vivo.

A large number of studies have shown that EGFR signalling plays an important role in the progression of colorectal cancer [38]. Overexpression of EGFR is observed in approximately $65 \%$ to $70 \%$ of colorectal cancer patients, and it is closely correlated with clinical stage, serosa invasion and lymph node involvement, indicating that EGFR-positive tumours may have a stronger ability to proliferate and invade and that EGFR can be used as an indicator of the progress and prognosis of colorectal cancer $[5,39,40]$. Therefore, EGFR is an important target for the inhibition of tumour growth. Currently, there are two main classes of drugs for EGFR targeting therapy: one is a monoclonal antibody directed against the extracellular domain of EGFR, such as cetuximab, panitumumab monoclonal antibody, etc., which binds to EGFR by competitive inhibition of the ligand, preventing EGFR activation [41, 42]; and the other is a small-molecule tyrosine kinase inhibitor, such as gefitinib, erlotinib, etc., that can enter the cell and directly bind the EGFR intracellular tyrosine kinase region, which interferes with the binding of ATP and inhibits tyrosine kinase activity to prevent auto phosphorylation, thus blocking EGFR pathway signal transduction $[43,44]$. However, many patients who initially respond to EGFR-targeted treatment eventually develop drug resistance that may be due to secondary EGFR mutations or other resistance mechanisms $[10,45]$. Hence, future studies should focus on the development of new drugs to overcome and prevent resistance [46]. Considering that miR-520a-3p is an upstream regulator of EGFR, it may be possible to up-regulate miR-520a-3p inhibit EGFR expression in vivo. The reexpression of miRNAs that are lost in cancers is a novel therapeutic strategy for cancers, and efforts to predictably alter oncogene profiles by increasing specific miRNAs, through either transfection or viral delivery methods, have demonstrated the potential utilities of miRNAs as therapeutic molecules in the treatment of human cancers. Future research is required to characterize the feasibility of targeting miR-520a-3p for colorectal cancer therapy and develop simple and cost-effective manipulation methods.

Taken together, we identified a novel function of miR-520a-3p in the suppression of cell migration, the acceleration of cell apoptosis, and cell cycle arrest by targeting EGFR in colorectal cancer. This conclusion is supported by several lines evidence: decreased expression of miR-520a-3p and increased expression of EGFR in human colorectal cancer tissues; three putative EGFR binding sites in the 3'-UTR that is subject to miR-520a-3p regulation; overexpression of miR-520a-3p attenuated colorectal cancer cell migration and stimulated cell apoptosis as well as cell cycle arrest at G0/G1 phase in colorectal cancer cells; miR-520a-3p decelerated tumour growth in xenograft mice; and EGFR and miR-520a$3 p$ have opposite biological functions in vivo. Thus, the miR-520a-3p-EGFR axis is a novel 


\section{Cellular Physiology Cell Physiol Biochem 2017;42:1559-1574 \begin{tabular}{c|l} 
DOI: 10.1159/000479397 & $\begin{array}{l}\text { @ } 2017 \text { The Author(s). Published by S. Karger AG, Basel } \\
\text { www.karger.com/cpb }\end{array}$
\end{tabular}}

Zhang et al.: Tumour Suppressor Role for miR-520a-3p in Colorectal Cancer

molecular mechanism that inhibits tumour growth and may serve as an excellent potential auxiliary treatment for colorectal cancer.

\section{Acknowledgements}

This work was supported by grants from the National Basic Research Program of China (973 Program) (No. 2014CB542300), the National Natural Science Foundation of China (No. 31271378, 81372838, J1103512 and J1210026), the Research Special Fund for Public Welfare Industry of Health (No. 201302018) and the Natural Science Foundation of Jiangsu Province (No. BE2016737).

\section{Disclosure Statement}

The authors declare no conflict of interest.

\section{References}

-1 Torre LA, Bray F, Siegel RL, Ferlay J, Lortet-Tieulent J, Jemal A: Global cancer statistics, 2012. CA Cancer J Clin 2015;65:87-108.

-2 Chen X, Ba Y, Ma L, Cai X, Yin Y, Wang K, Guo J, Zhang Y, Chen J, Guo X, Li Q, Li X, Wang W, Zhang Y, Wang J, Jiang X, Xiang Y, Xu C, Zheng P, Zhang J, Li R, Zhang H, Shang X, Gong T, Ning G, Wang J, Zen K, Zhang J, Zhang CY: Characterization of microRNAs in serum: a novel class of biomarkers for diagnosis of cancer and other diseases. Cell Res 2008;18:997-1006.

-3 Moroni M, Veronese S, Benvenuti S, Marrapese G, Sartore-Bianchi A, Di Nicolantonio F, Gambacorta M, Siena S, Bardelli A: Gene copy number for epidermal growth factor receptor (EGFR) and clinical response to antiEGFR treatment in colorectal cancer: a cohort study. Lancet Oncol 2005;6:279-286.

4 Nicholson RI, Gee JM, Harper ME: EGFR and cancer prognosis. Eur J Cancer 2001;37 Suppl 4:S9-15.

5 Spano JP, Lagorce C, Atlan D, Milano G, Domont J, Benamouzig R, Attar A, Benichou J, Martin A, Morere JF, Raphael M, Penault-Llorca F, Breau JL, Fagard R, Khayat D, Wind P: Impact of EGFR expression on colorectal cancer patient prognosis and survival. Ann Oncol 2005;16:102-108.

6 Porebska I, Harlozinska A, Bojarowski T: Expression of the tyrosine kinase activity growth factor receptors (EGFR, ERB B2, ERB B3) in colorectal adenocarcinomas and adenomas. Tumour Biol 2000;21:105-115.

7 Douillard JY, Siena S, Cassidy J, Tabernero J, Burkes R, Barugel M, Humblet Y, Bodoky G, Cunningham D, Jassem J, Rivera F, Kocakova I, Ruff P, Blasinska-Morawiec M, Smakal M, Canon JL, Rother M, Oliner KS, Tian Y, Xu F, Sidhu R: Final results from PRIME: randomized phase III study of panitumumab with FOLFOX4 for first-line treatment of metastatic colorectal cancer. Ann Oncol 2014;25:1346-1355.

8 Gustavsson B, Carlsson G, Machover D, Petrelli N, Roth A, Schmoll HJ, Tveit KM, Gibson F: A review of the evolution of systemic chemotherapy in the management of colorectal cancer. Clin Colorectal Cancer 2015;14:1-10.

-9 Arena S, Bellosillo B, Siravegna G, Martinez A, Canadas I, Lazzari L, Ferruz N, Russo M, Misale S, Gonzalez I, Iglesias M, Gavilan E, Corti G, Hobor S, Crisafulli G, Salido M, Sanchez J, Dalmases A, Bellmunt J, De Fabritiis G, Rovira A, Di Nicolantonio F, Albanell J, Bardelli A, Montagut C: Emergence of Multiple EGFR Extracellular Mutations during Cetuximab Treatment in Colorectal Cancer. Clin Cancer Res 2015;21:2157-2166.

10 Bardelli A, Siena S: Molecular mechanisms of resistance to cetuximab and panitumumab in colorectal cancer. J Clin Oncol 2010;28:1254-1261.

-11 Diaz LA, Jr., Williams RT, Wu J, Kinde I, Hecht JR, Berlin J, Allen B, Bozic I, Reiter JG, Nowak MA, Kinzler KW, Oliner KS, Vogelstein B: The molecular evolution of acquired resistance to targeted EGFR blockade in colorectal cancers. Nature 2012;486:537-540.

12 Bartel DP: MicroRNAs: target recognition and regulatory functions. Cell 2009;136:215-233.

13 Bartel DP: MicroRNAs: genomics, biogenesis, mechanism, and function. Cell 2004;116:281-297. 


\section{Cellular Physiology Cell Physiol Biochem 2017;42:1559-1574 \begin{tabular}{c|l|l}
\hline DOI: 10.1159/000479397 & () 2017 The Author(s). Published by S. Karger AG, Basel
\end{tabular} and Biochemistry Published online: July 21, 2017 www.karger.com/cpb}

Zhang et al.: Tumour Suppressor Role for miR-520a-3p in Colorectal Cancer

14 Xie T, Huang M, Wang Y, Wang L, Chen C, Chu X: MicroRNAs as Regulators, Biomarkers and Therapeutic Targets in the Drug Resistance of Colorectal Cancer. Cell Physiol Biochem 2016;40:62-76.

-15 Han RR, Sun QQ, Wu JB, Zheng PY, Zhao GQ: Sodium Butyrate Upregulates miR-203 Expression to Exert AntiProliferation Effect on Colorectal Cancer Cells. Cellular Physiology and Biochemistry 2016;39:1919-1929.

16 Wu N, Song Y, Pang L, Chen Z: CRCT1 regulated by microRNA-520 g inhibits proliferation and induces apoptosis in esophageal squamous cell cancer. Tumour Biol 2016;37:8271-8279.

17 Yan L, Yu J, Tan F, Ye GT, Shen ZY, Liu H, Zhang Y, Wang JF, Zhu XJ, Li GX: SP1-mediated microRNA-520d$5 p$ suppresses tumor growth and metastasis in colorectal cancer by targeting CTHRC1. Am J Cancer Res 2015;5:1447-1459.

18 Zhang R, Liu C, Niu Y, Jing Y, Zhang H, Wang J, Yang J, Zen K, Zhang J, Zhang CY, Li D: MicroRNA-128-3p regulates mitomycin C-induced DNA damage response in lung cancer cells through repressing SPTAN1. Oncotarget 2016;10.18632/oncotarget.12300

19 Di Leva G, Croce CM: miRNA profiling of cancer. Curr Opin Genet Dev 2013;23:3-11.

20 Wei W, Yang Y, Cai J, Cui K, Li RX, Wang H, Shang X, Wei D: MiR-30a-5p Suppresses Tumor Metastasis of Human Colorectal Cancer by Targeting ITGB3. Cell Physiol Biochem 2016;39:1165-1176.

-21 Liu X, Xie T, Mao X, Xue L, Chu X, Chen L: MicroRNA-149 Increases the Sensitivity of Colorectal Cancer Cells to 5-Fluorouracil by Targeting Forkhead Box Transcription Factor FOXM1. Cell Physiol Biochem 2016;39:617-629.

22 Zhou L, Xu Z, Ren X, Chen K, Xin S: MicroRNA-124 (MiR-124) Inhibits Cell Proliferation, Metastasis and Invasion in Colorectal Cancer by Downregulating Rho-Associated Protein Kinase 1(ROCK1). Cell Physiol Biochem 2016;38:1785-1795.

-23 Li HT, Zhang H, Chen Y, Liu XF, Qian J: MiR-423-3p Enhances Cell Growth Through Inhibition of p21Cip1/ Waf1 in Colorectal Cancer. Cell Physiol Biochem 2015;37:1044-1054.

-24 Medina PP, Nolde M, Slack FJ: OncomiR addiction in an in vivo model of microRNA-21-induced pre-B-cell lymphoma. Nature 2010;467:86-90.

-25 Fang YT, Sun B, Xiang JB, Chen ZY: MiR-301a Promotes Colorectal Cancer Cell Growth and Invasion by Directly Targeting SOCS6. Cell Physiol Biochem 2015;35:227-236.

-26 Zhu S, Wu H, Wu F, Nie D, Sheng S, Mo YY: MicroRNA-21 targets tumor suppressor genes in invasion and metastasis. Cell Res 2008;18:350-359.

27 Zhang WB, Zou C, Pan L, Xu Y, Qi WD, Ma G, Hou YZ, Jiang PC: MicroRNA-140-5p Inhibits the Progression of Colorectal Cancer by Targeting VEGFA. Cell Physiol Biochem2015;37:1123-1133.

28 Xu K, Liu XB, Mao XB, Xue LJ, Wang R, Chen LB, Chu XY: MicroRNA-149 Suppresses Colorectal Cancer Cell Migration and Invasion by Directly Targeting Forkhead Box Transcription Factor FOXM1. Cell Physiol Biochem 2015;35:499-515.

29 Kota J, Chivukula RR, O‘Donnell KA, Wentzel EA, Montgomery CL, Hwang HW, Chang TC, Vivekanandan P, Torbenson M, Clark KR, Mendell JR, Mendell JT: Therapeutic microRNA delivery suppresses tumorigenesis in a murine liver cancer model. Cell 2009;137:1005-1017.

-30 Schetter AJ, Leung SY, Sohn JJ, Zanetti KA, Bowman ED, Yanaihara N, Yuen ST, Chan TL, Kwong DL, Au GK, Liu CG, Calin GA, Croce CM, Harris CC: MicroRNA expression profiles associated with prognosis and therapeutic outcome in colon adenocarcinoma. JAMA 2008;299:425-436.

-31 Bader AG, Brown D, Winkler M: The promise of microRNA replacement therapy. Cancer Res 2010;70:70277030.

-32 Iorio MV, Croce CM: MicroRNA dysregulation in cancer: diagnostics, monitoring and therapeutics. A comprehensive review. EMBO Mol Med 2012;4:143-159.

-33 Zhu K, Ding H, Wang W, Liao Z, Fu Z, Hong Y, Zhou Y, Zhang CY, Chen X: Tumor-suppressive miR-218$5 p$ inhibits cancer cell proliferation and migration via EGFR in non-small cell lung cancer. Oncotarget 2016;7:28075-28085.

-34 Liu Y, Uzair Ur R, Guo Y, Liang H, Cheng R, Yang F, Hong Y, Zhao C, Liu M, Yu M, Zhou X, Yin K, Chen J, Zhang J, Zhang CY, Zhi F, Chen X: miR-181b functions as an oncomiR in colorectal cancer by targeting PDCD4. Protein Cell 2016;7:722-734.

-35 Keklikoglou I, Koerner C, Schmidt C, Zhang JD, Heckmann D, Shavinskaya A, Allgayer H, Guckel B, Fehm T, Schneeweiss A, Sahin O, Wiemann S, Tschulena U: MicroRNA-520/373 family functions as a tumor suppressor in estrogen receptor negative breast cancer by targeting NF-kappaB and TGF-beta signaling pathways. Oncogene 2012;31:4150-4163. 


\section{Cellular Physiology Cell Physiol Biochem 2017;42:1559-1574 \begin{tabular}{l|l|l|} 
DOI: 10.1159/000479397 & 02017 The Author(s). Published by S. Karger AG, Basel \\
\hline
\end{tabular} \\ Zhang et al.: Tumour Suppressor Role for miR-520a-3p in Colorectal Cancer}

-36 Huang Q, Gumireddy K, Schrier M, le Sage C, Nagel R, Nair S, Egan DA, Li A, Huang G, Klein-Szanto AJ, Gimotty PA, Katsaros D, Coukos G, Zhang L, Pure E, Agami R: The microRNAs miR-373 and miR-520c promote tumour invasion and metastasis. Nat Cell Biol 2008;10:202-210.

37 Yang K, Handorean AM, Iczkowski KA: MicroRNAs 373 and 520c are downregulated in prostate cancer, suppress CD44 translation and enhance invasion of prostate cancer cells in vitro. Int J Clin Exp Pathol 2009;2:361-369.

-38 Sartore-Bianchi A, Martini M, Molinari F, Veronese S, Nichelatti M, Artale S, Di Nicolantonio F, Saletti P, De Dosso S, Mazzucchelli L, Frattini M, Siena S, Bardelli A: PIK3CA mutations in colorectal cancer are associated with clinical resistance to EGFR-targeted monoclonal antibodies. Cancer Res 2009;69:18511857.

-39 Italiano A, Saint-Paul MC, Caroli-Bosc FX, Francois E, Bourgeon A, Benchimol D, Gugenheim J, Michiels JF: Epidermal growth factor receptor (EGFR) status in primary colorectal tumors correlates with EGFR expression in related metastatic sites: biological and clinical implications. Ann Oncol 2005;16:1503-1507.

-40 Flora M, Piana S, Bassano C, Bisagni A, De Marco L, Ciarrocchi A, Tagliavini E, Gardini G, Tamagnini I, Banzi C, Bisagni G: Epidermal growth factor receptor (EGFR) gene copy number in colorectal adenomacarcinoma progression. Cancer Genet 2012;205:630-635.

-41 Allegra CJ, Jessup JM, Somerfield MR, Hamilton SR, Hammond EH, Hayes DF, McAllister PK, Morton RF, Schilsky RL: American Society of Clinical Oncology provisional clinical opinion: testing for KRAS gene mutations in patients with metastatic colorectal carcinoma to predict response to anti-epidermal growth factor receptor monoclonal antibody therapy. J Clin Oncol 2009;27:2091-2096.

42 Heinemann V, Stintzing S, Kirchner T, Boeck S, Jung A: Clinical relevance of EGFR- and KRAS-status in colorectal cancer patients treated with monoclonal antibodies directed against the EGFR. Cancer Treat Rev 2009;35:262-271.

43 Cascinu S, Berardi R, Salvagni S, Beretta GD, Catalano V, Pucci F, Sobrero A, Tagliaferri P, Labianca R, Scartozzi M, Crocicchio F, Mari E, Ardizzoni A: A combination of gefitinib and FOLFOX-4 as first-line treatment in advanced colorectal cancer patients. A GISCAD multicentre phase II study including a biological analysis of EGFR overexpression, amplification and NF-kB activation. Br J Cancer 2008;98:71-76.

44 Koizumi F, Kanzawa F, Ueda Y, Koh Y, Tsukiyama S, Taguchi F, Tamura T, Saijo N, Nishio K: Synergistic interaction between the EGFR tyrosine kinase inhibitor gefitinib („Iressa“) and the DNA topoisomerase I inhibitor CPT-11 (irinotecan) in human colorectal cancer cells. Int J Cancer 2004;108:464-472.

45 Baselga J: Targeting tyrosine kinases in cancer: the second wave. Science 2006;312:1175-1178.

-46 de Castro-Carpeno J, Belda-Iniesta C, Casado Saenz E, Hernandez Agudo E, Feliu Batlle J, Gonzalez Baron M: EGFR and colon cancer: a clinical view. Clin Transl Oncol 2008;10:6-13. 